\title{
Electromyographic responses to Nordic curl and prone leg curl exercises in football players
}

\author{
Murat Çilli ${ }^{\mathrm{ABCDE}}$, Merve N. Yaşar ${ }^{\mathrm{ABCDE}}$, Onur Çakir ${ }^{\mathrm{ABCDE}}$ \\ Faculty of Sport Sciences, Sakarya University of Applied Sciences, Sakarya, Turkey
}

Authors' contributions: A - Study design; B - Data collection; C - Statistical analysis; D - Manuscript Preparation; E-Funds Collection.

\begin{abstract}
Background The aim of this study is to examine the electromyographic responses to Nordic curl and prone leg curl and Study Aim exercises, having two different mechanics.

Material and The athletes performed the prone leg curl and Nordic curl exercises in random order, 6 repetitions each. Methods Electromyographic data of semimemranosus, semitendinosus, biceps femoris and rectus femoris muscles were recorded by 8-channel electromyography in order to examine the muscle responses to exercises. Total duration of exercise, cumulative integrated electromyographic values and muscle activation rates in 5 different intensity zones determined according to MVC\% values have been compared.

Results Prone leg curl exercise occurred in less time than Nordic curl exercise. According to the cumulative integrated electromyography data results, all muscles showed similar muscle activation in both exercises. Comparing the muscle activation rates in the five intensity zones, more muscle activity was observed for Nordic curl exercise in the first intensity zone, while prone leg curl exercise was more active in the third and fourth zones. During the prone leg curl exercise, the muscle activation rate of the dominant leg is higher in the first intensity zone, whereas the non-dominant leg in the fourth intensity zone has a higher muscle activation. During the Nordic curl exercise, the muscle activation rates of the dominant leg in the first and fifth intensity zones are higher, whereas the nondominant leg in the fourth intensity zone is higher.

Conclusions Prone leg curl exercises can be preferred in order to stimulate high muscle activation in a short time. Comparing the two exercises there was no significant difference in muscle activity in dominant and nondominant legs.

Keywords: $\quad$ muscle activation, intensity zones, performance, exercise, training
\end{abstract}

\section{Introduction}

Football, which has reached 275 million active players today, is the arguably most popular sport in the world [1]. Football is a contact sport with high technical, tactical and physiological demands $[2,3]$. Therefore, the risk of injury in football is quite high [4]. For amateur footballers, the rate of injury is even higher. In amateur football, it has been reported that injuries occur on average 20 to 37 times in every 1000 matches and 2 to 4 times in every 1000 training sessions [5]. Among the injuries that occur, hamstring muscle injuries are seen as one of the most common lower extremity musculoskeletal injuries [6-9]. While an average of 5-6 hamstring injuries occurs in each team during a season, it accounts for $12 \%$ to $16 \%$ of all injuries in adult men's football [10]. Hamstring muscle injuries account for about $16 \%$ of all injuries in men's amateur football. However, compared to other sports, hamstring muscle injury repetition rate is higher in football, and this rate is $16[11,12]$. While mild muscle strains can recover with a 2-6-week rest, more severe tears and ruptures may require surgical interventions and the treatment period may take months. They also have a repetition rate of up to $34 \%$, especially in the first few weeks after returning to the game $[9,13]$. The hamstring muscle group plays an active role in branches that include deceleration, acceleration, jumping, hitting and changing

(c) Murat Çilli, Merve N. Yaşar, Onur Çakir, 2021

doi:10.15561/20755279.2021.0505 direction [10, 14, 15]. Hamstring injuries are generally non-contact injuries and often occur as a result of sprinting $[16,17]$.

In the extant literature, the risk factors associated with hamstring injuries have been investigated, and the idea that such injuries are multifactorial in nature has been generally accepted [18]. However, it is known that variables such as athlete's age, playing position, hamstring injury history, muscle structure, fatigue, flexibility and strength are effective in hamstring injuries [19]. In particular, the differences in strength between the agonist and antagonist muscles seem to trigger the risk of injury [20]. As a result of unilateral loading, asymmetric strength development may occur between agonist antagonist muscles. Athletes often try to develop the quadriceps muscle and neglect the hamstring muscle group. As a result, a strength imbalance might occur and the risk of injury increases [10]. It has been reported that muscle imbalances in the knee joint affect the occurrence of injury, and players with untreated strength imbalances have an approximately 4.66 times higher risk of injury [21]. As another factor, it is known that the imbalance of strength between the dominant (D) and non-dominant (ND) leg plays a role in injuries. In single-leg dominant sports such as football, a significant asymmetry may develop between dominant and non-dominant legs [22]. It is emphasized that both legs should be used effectively and efficiently in order to display a high-performance level in football $[23,24]$. 
Strength differences and imbalance between dominant and non-dominant legs can be observed especially during the return to the field after an injury [25]. It is aimed to increase and strengthen muscle activation by including some exercises in the prevention and rehabilitation of hamstring muscle group injuries. Choosing appropriate exercises to strengthen the hamstring muscle is important in minimizing injuries [26]. There are many different resistance exercises for the hamstring muscle group. These exercises can be evaluated in two separate groups as resistance exercises performed on the field with body weight and on machines at gyms. It is known that the prone leg curl (PLC) exercise is preferred frequently among hamstring exercises performed on machines at gyms. In the PLC exercise, the athlete performs flexion and extension exercises in the knee joint against a certain resistance. Eccentric and concentric muscle activation occurs in the hamstring muscle group. On the other hand, it has been observed that eccentric exercises performed with body weight have positive effects, including reduced risk of hamstring muscle and tendon injuries, improved lower extremity strength and sprinting ability [27]. Eccentric exercise has been successfully used for injury prevention in a case study involving an Australian Footballer with recurrent hamstring injuries [6]. A decrease in both the frequency and severity of hamstring injuries has been observed with the addition of the widely used Nordic curl (NC) exercise, to the training program of professional rugby [28] and elite football players [10]. In a similar study conducted on football players, it was reported that the hamstring injury rate decreased in athletes who applied the NC in the pre-season period. It has been observed that there are reductions of $60 \%$ and $85 \%$ in new and recurrent injuries, respectively [29]. Gabbe et al. [30] reported a hamstring injury frequency of $4 \%$ in the intervention group versus $13 \%$ in the control group. Interestingly, another study compared conventional hamstring exercises with the $\mathrm{NC}$, and it was observed that a 10 -week the NC study was more effective in developing maximum eccentric hamstring muscle strength [31]. Although the $\mathrm{NC}$ is a popular training exercise widely used by strength and conditioning coaches and physical therapists, the question of hamstring activation level has been included in a limited number of studies [14, 32]. Depending on the type of exercise, muscle activation time and the stress level on the muscle change.

It can be argued that examining the effects of the PLC and the NC exercises on hamstring muscle group is important in choosing the appropriate exercise. Understanding muscle responses to exercises can be effective for the design of strength training and injury prevention programs [33]. In this study, it is aimed to examine the muscle responses to the $\mathrm{NC}$ exercises performed on the field with body weight and the PLC exercises performed on the machine.

\section{Material and Methods \\ Participants}

The study group was composed of 20 active athletes (mean \pm SD age: $17.3 \pm 0.80$ years, height; $178 \pm 0.06 \mathrm{~cm}$, weight; $68.3 \pm 8.34 \mathrm{~kg}$, BMI; $21.7 \pm 2.51 \mathrm{~kg} / \mathrm{m}^{2}$, body fat; $11.86 \% \pm 4.30$ ) who voluntarily agreed to participate, were in the U-19 football team, and did not have an injury that would interfere with the study process. The athletes had 5 years of athletic background and trained at least four times a week. For the study group, the team who had training experience in hamstring exercises with two different mechanical properties were chosen. The athletes were informed about the tests as well as the possible risks and benefits. Before the study, ethical approval (E-26428519044-8855) was received from Sakarya University of Applied Sciences Ethics Committee.

\section{Research Design.}

\section{Experimental Approach to the Problem:}

The NC is a hamstring exercise that can be easily applied on the field without any special equipment, while the PLC is a hamstring exercise that is performed on a machine and is commonly used in gyms. Even though both of the exercises are used for the hamstring muscle development and rehabilitation, they have different mechanics. This study was carried out to investigate whether the hamstring muscle activity differentiates according to these exercises performed with different mechanics. The athletes performed 10 minutes of general warmup exercises (jogging) and a special warm-up protocol that included 10 minutes of running specific to football, jumping, and dynamic stretching exercises. To warm up for the tests, PLC and NC exercises were repeated a few times. Afterwards, athletes' electromyographic (EMG) signals during the maximal voluntary contraction (MVC) of the hamstring and quadriceps muscles were recorded. The athletes performed 6 repetitions of the PLC and NC exercises in random order at their own speed. During both exercises, surface EMG signals of SM, ST, BF and RF muscles were recorded with the 8-channel Delsys Bagnoli EMG system at $2000 \mathrm{~Hz}$ sampling frequency.

\section{Procedures}

The hair on athletes' hamstring and quadriceps was shaved off and their skin was cleansed by a liquid skin cleanser that contains $70 \%$ of alcohol. The electrodes were placed on the muscle belly point of the SM, ST, BF, and RF muscles with medical flexible plasters $(10 \times 10 \mathrm{~mm})$ in accordance with the Seniam guidelines [34]. The quality of the signal was checked after all electrodes were placed. Then, the MVC measurement positions, which were used by Konrad [35], (Figure 1,2) were applied to determine the MVC values of the athletes' hamstring and quadriceps muscles.

The MVC measurements were performed three times. Upon instruction, the athlete was asked to perform maximal contraction for 5 seconds and rest for 5 second afterwards. The athletes rested for two minutes between MVC measurements of the hamstring and quadriceps muscles. After the MVC measurements, the athletes performed the PLC and $\mathrm{NC}$ exercises with two-minute intervals in random order. The exercises were performed in 6 repetitions and the athletes determined the speed of the exercises themselves. In order to equalize the 


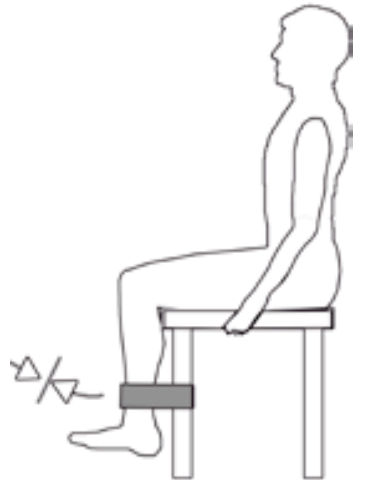

Figure 1. MVC measurement of the quadriceps muscle [35]

resistance during both exercises, upper extremity body mass was calculated with the segmentation method for the athletes' resistance during the $\mathrm{NC}$ exercise. Then, the weight at the same value with the upper extremity was determined as the resistance during the PLC exercise that is performed on the machine. The segmentation procedure was carried out by proportioning the body weight to the relative weight values of the upper extremity body parts (Table 1).

Table 1. Relative weight values of body parts [35]

\begin{tabular}{lccccc}
\hline Body Part & Head & Body & $\begin{array}{l}\text { Upper } \\
\text { Arm }\end{array}$ & $\begin{array}{l}\text { Fore } \\
\text { Arm }\end{array}$ & Hand \\
\hline $\begin{array}{l}\text { Relative } \\
\text { Weight }\end{array}$ & 0.073 & 0.507 & 0.026 & 0.016 & 0.007 \\
\hline
\end{tabular}

Anthropometric Measurements

Athletes' body weight, body fat and body mass indices were measured using the Tanita (Segmental Body Composition Monitor InnerScan BC-545N -Japan); their height were measured using a portable stadiometer with 1 mm accuracy (Seca 213 Germany).

Prone Leg Curl Exercise

The athlete laid face down on the PLC machine and the machine pads were adjusted on the achilles tendon (Figure 3). He pulled the pad toward the hamstring muscle group at his own pace, waited for one to two seconds when the pad touched the hamstring muscle group and then returned to the starting position. The athlete was instructed not to move his knee joint during the exercise. The exercise was performed 6 times.

\section{Nordic Curl Exercise}

An assistant applied pressure on the lateral malleolus to stabilize the athlete and isolate the hamstring muscles (Figure 4). The athlete tried to maintain his position while he was stabilized by his ankles and slowly leaned forward to make his body as straight as he could. Then, returned to the starting position by pushing himself up with his arms from the ground. The athlete was instructed not to move his hips and that the body should be completely straight from head to knees during the exercise. The assistant firmly held the athlete's lower legs during the exercise. The head, upper body, hips and thighs lined up. The exercise was performed 6 times.

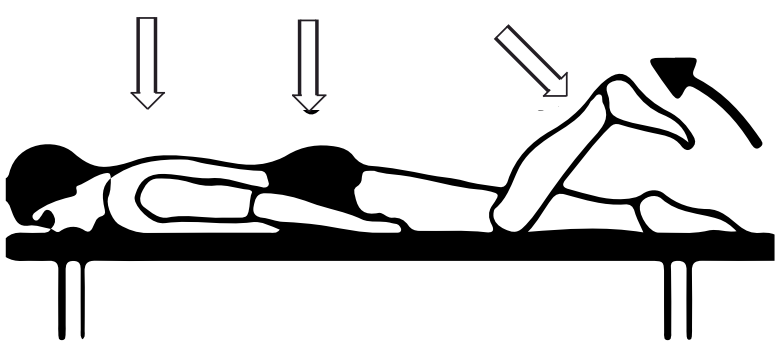

Figure 2. MVC measurement of the hamstring muscle [35].

EMG Analysis

Band pass filter and moving average procedures were applied on the raw EMG data within the range of 10-500 Hz. The total duration of PLC and NC exercises were calculated. The cumulative integrated EMG values of each muscle during the exercises were calculated. $\mathrm{MVC} \%$ values were calculated using the EMG data of the maximal isometric contraction (figure 5). The exercises were categorized into 5 different intensity zones based on the MVC\% values $(0 \%-20 \%, 20 \%-40 \% 40 \%-60 \%, 60 \%$ $80 \%$ and $80 \%-+)$. The intensity zones were numbered from 1 to 5 , referring to the lowest and highest intensity, respectively (Table 2). The total duration of the exercise, which refers to the activity of each muscle on the intensity zones, was calculated in percentages.

\section{Statistical Analysis}

The normal distribution of the data obtained from EMG analyses was analysed with the Shapiro Wilk test. The duration in which the PLC and NC exercises were performed, muscle activity during the exercises (cumulative integrated EMG), activity rates of the PLC and $\mathrm{NC}$ exercises in the five intensity zones based on the MVC\% were compared using the Wilcoxon Signed-Rank Test.

Table 2. Intensity Zones (IZ) determined based on the MVC\% values

\begin{tabular}{lllll}
\hline \multicolumn{2}{l}{ Intensity Zones } & & & \\
\hline $\begin{array}{l}0 \%-20 \% \\
\text { of MVC\% }\end{array}$ & $\begin{array}{l}20 \%-40 \% \\
\text { of MVC\% }\end{array}$ & $\begin{array}{l}40 \%-60 \% \\
\text { of MVC\% }\end{array}$ & $\begin{array}{l}60 \%-80 \% \\
\text { of MVC\% }\end{array}$ & $\begin{array}{l}80 \% \\
\text { and + of } \\
\text { MVC\% }\end{array}$ \\
\hline 1 st IZ & 2nd IZ & 3rd IZ & 4th IZ & 5th IZ
\end{tabular}

The Freidman Test was used to compare the activity rates of each muscle in the 5 intensity zones during both exercises. Pairwise Multiple Comparison Test was used to determine the source of the difference. Statistical significance for all analyses was set at $\mathrm{p}<0.05$.

\section{Results}

The results obtained from the D leg and ND leg EMG data that belong to muscle responses given to PLC and $\mathrm{NC}$ exercises are presented in the tables and graphs below.

Total mean durations of the PLC and NC exercises 


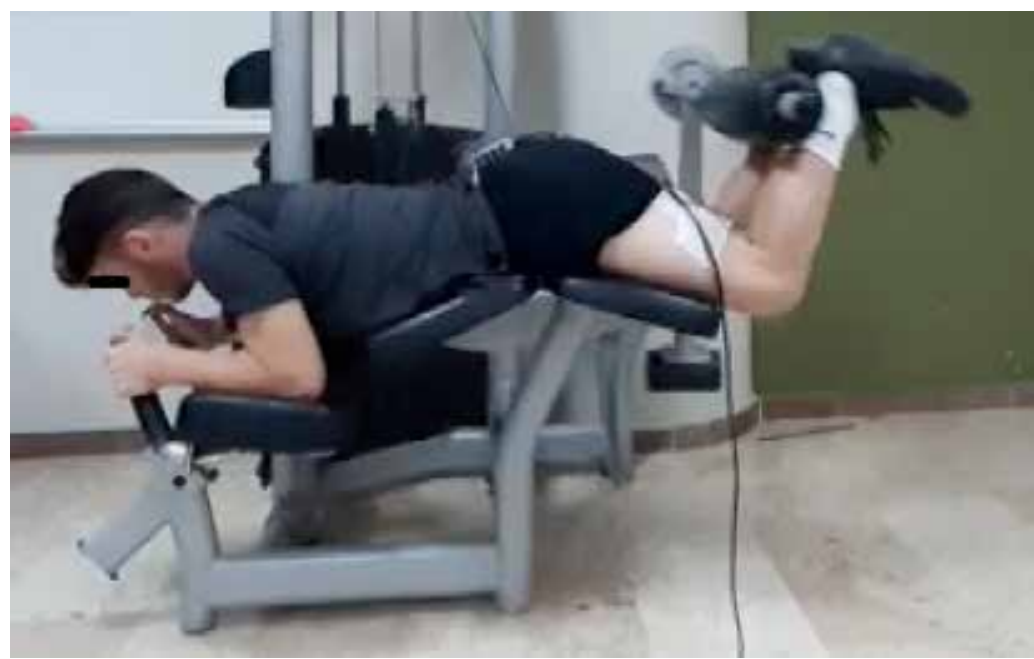

Figure 3. Prone Leg Curl Exercise

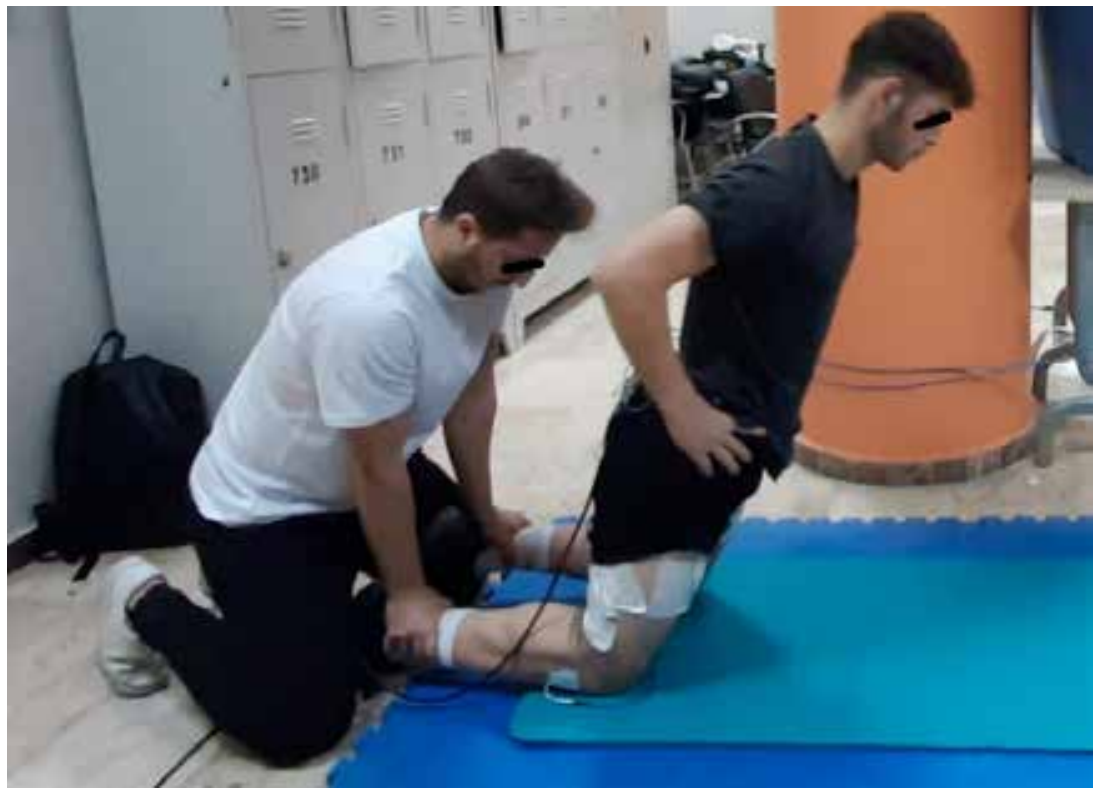

Figure 4. Nordic Curl Exercise

after 6 repetitions were compared and it was observed that the PLC exercise was performed in a shorter time than the NC exercise (Table 3) $(\mathrm{p}<0.05)$.

Table 3. Durations of the PLC and NC Exercises

\begin{tabular}{lll}
\hline Exercises & Prone Leg Curl & Nordic Curl \\
\hline Time (s) & 26.65 & 30.11 \\
\hline
\end{tabular}

The total muscle activity of each muscle during PLC and NC exercises were compared using cumulative integrated EMG data (Figure 6). It was observed that cumulative integrated EMG values during PLC and NC exercises were similar for each muscle ( $p>0.05)$.

Activity rates of the muscles analysed in two different exercises in different intensity zones were compared in Figure 7. The results showed that the activity rate of the NC exercise was higher for the ST muscle of the ND leg in the first intensity zone (PLC: $32 \%, \mathrm{NC}: 42 \%)(\mathrm{p}<0.05)$. In the third intensity zone, the activity rate of the PLC exercise was higher for the BF muscle of the ND leg (PLC: $25 \%, \mathrm{NC}: 19 \%)(\mathrm{p}<0.05)$. Activity rate of the PLC exercise was higher for BF muscle of the D leg in the fourth intensity zone (PLC: 14\%, NC: $9 \%)(p<0.05)$. The activity rates of the muscles in both exercises were similar in the second and fifth intensity zones $(p>0.05)$.

Figure 8 shows the activity rates of D leg and ND leg muscles in different intensity zones during the PLC exercise. The results showed that the activity rate of the D leg was higher for the ST muscle in the first intensity zone $(\mathrm{D}: 37 \%, \mathrm{ND}: 30 \%)(\mathrm{p}<0.05)$. In the fourth intensity zone, the activity rate of the ND leg was higher for the ST muscle $(\mathrm{D}: 5 \%, \mathrm{ND}: 10 \%)(\mathrm{p}<0.05)$. The activity rates of $\mathrm{D}$ and ND legs were similar in the other intensity zones $(p>0.05)$.

Figure 9 shows the activity rates of D leg and ND leg muscles in different intensity zones during the $\mathrm{NC}$ exercise. The results showed that the activity rate of the D leg was higher for the ST muscle in the first intensity zone (D:51\%, ND:42\%) $(\mathrm{p}<0.05)$. The activity rates of $\mathrm{D}$ and ND legs were similar in the second and third intensity zones $(p>0.05)$. In the fourth intensity zone, the activity rate of the ND leg was higher for the ST muscle 
Table 2. Intensity Zones (IZ) determined based on the MVC\% values

\begin{tabular}{lllll}
\hline Intensity Zones & & & \\
\hline $0 \%-20 \%$ of MVC\% & $20 \%-40 \%$ of MVC\% & $40 \%-60 \%$ of MVC\% & $\mathbf{6 0 \% - 8 0 \% ~ o f ~ M V C \% ~}$ & $\mathbf{8 0 \%}$ and + of MVC\% \\
\hline $1^{\text {st } I Z}$ & $2^{\text {nd }} I Z$ & $3^{\text {rd }} I Z$ & $4^{\text {th }} I Z$ & $5^{\text {th }} I Z$ \\
\hline
\end{tabular}

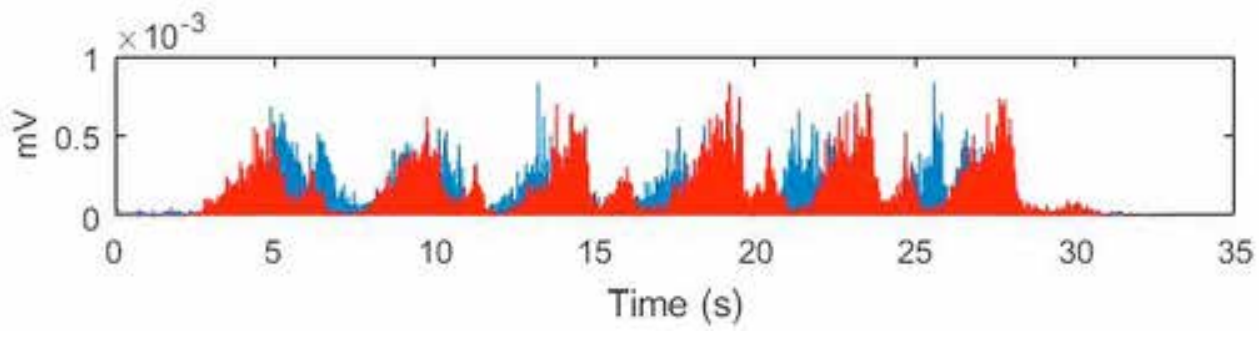

a. Filtered EMG signal of semitendinosus muscle

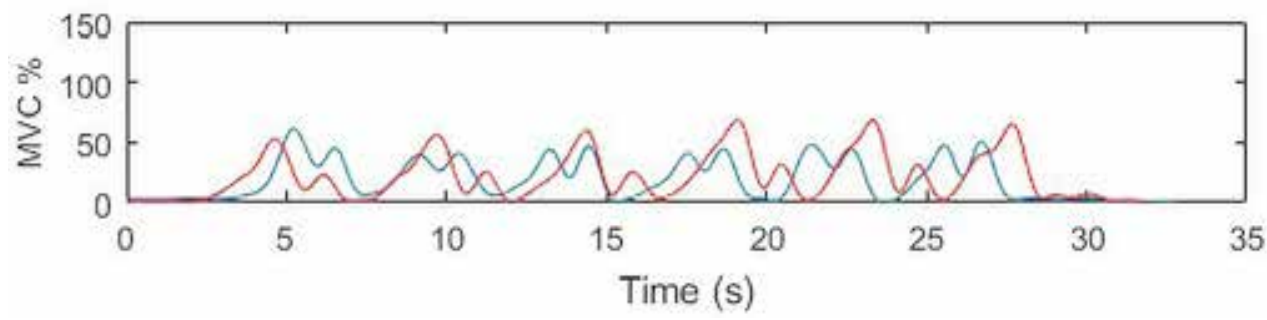

b. MVC\% of EMG signal of semitendinosus muscle

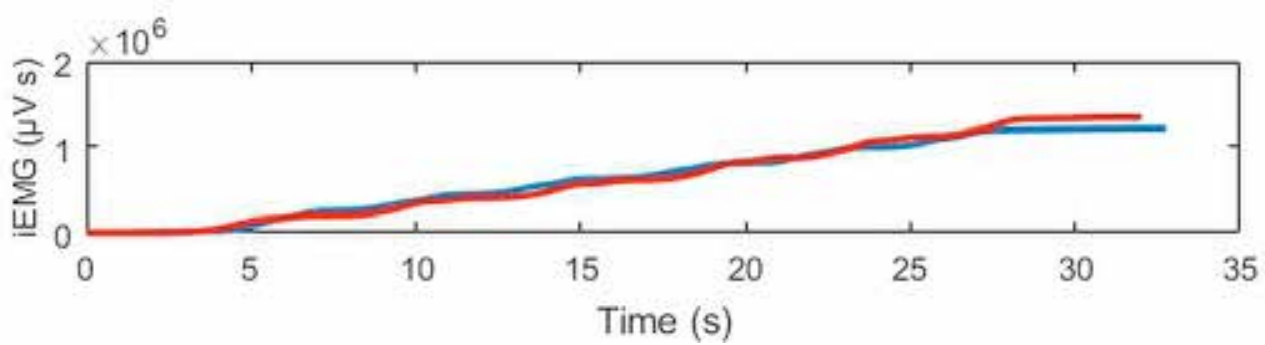

c. Cumulative Integrate EMG of semitendinosus muscle

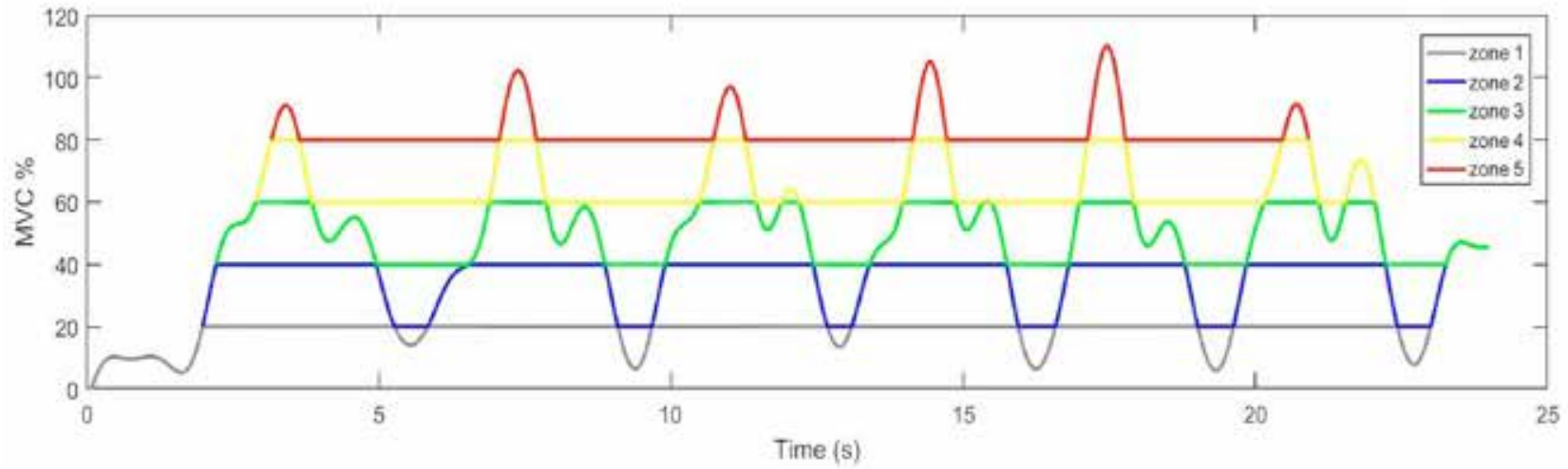

d. Muscle activation of semitendinosus muscle for 5 intensity zones

Figure 5. Sample data for the analysis process of EMG data during the PLC and NC exercises: a. EMG data that was applied a band pass filter within the range of $10-500 \mathrm{~Hz}$ : b. MVC\% values that were normalized using the EMG values during the maximal isometric contraction: c. Cumulative integrated EMG data: d. Five different intensity zones that were created based on the MVC\% values. 


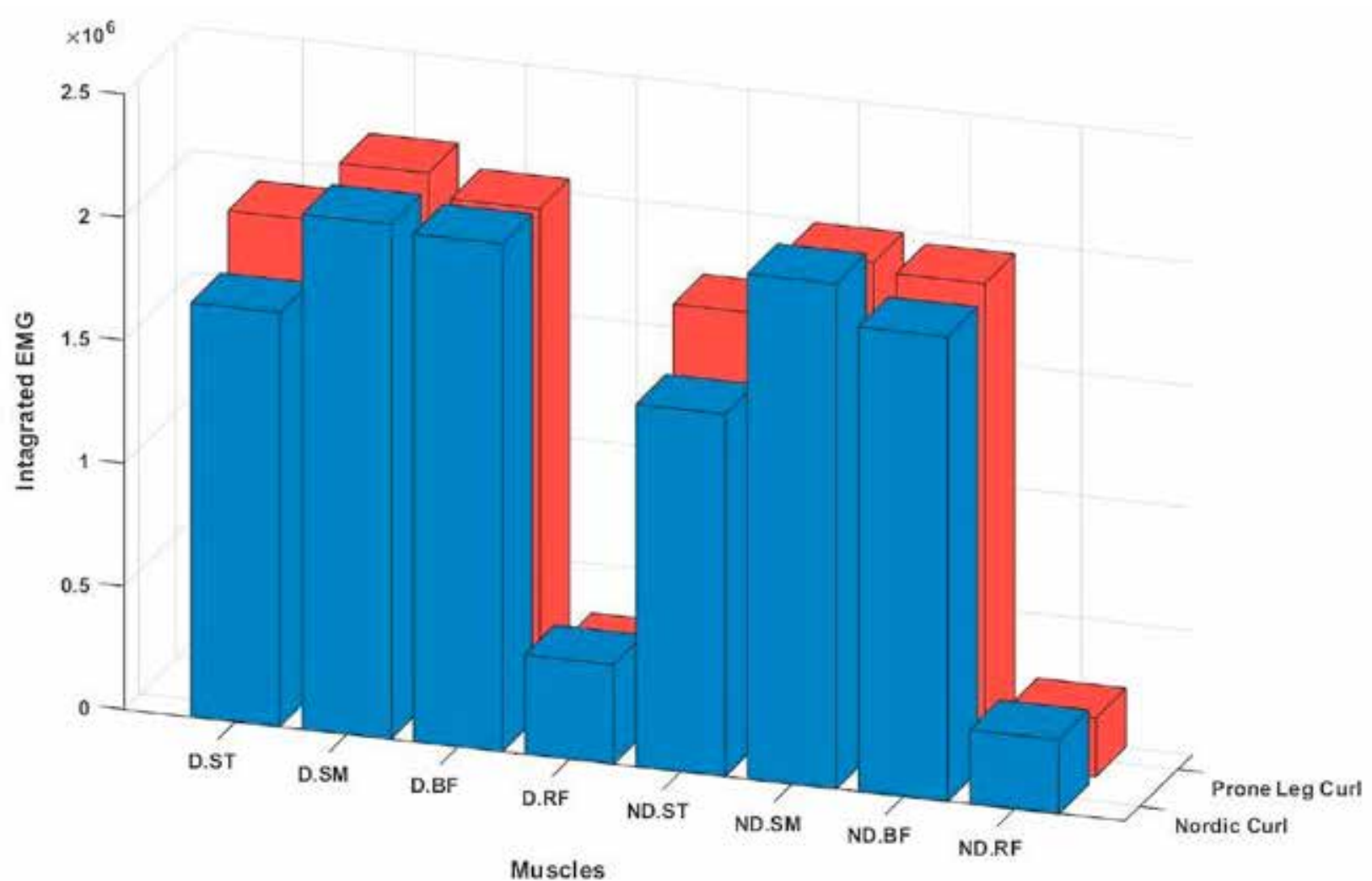

Figure 6. Comparison of Cumulative Integrated EMG Values of Each Muscle During PLC and NC Exercises: D.ST: Dominant semitendinosus, D.SM: Dominant semimembranosus, D.BF: Dominant Biceps femoris, D.RF: Dominant rectus femoris, ND.ST: Nondominant semitendinosus, ND.SM: Nondominant semimembranosus, ND.BF: Nondominant bicepsfemoris, ND.RF: Nondominant rectus femoris.

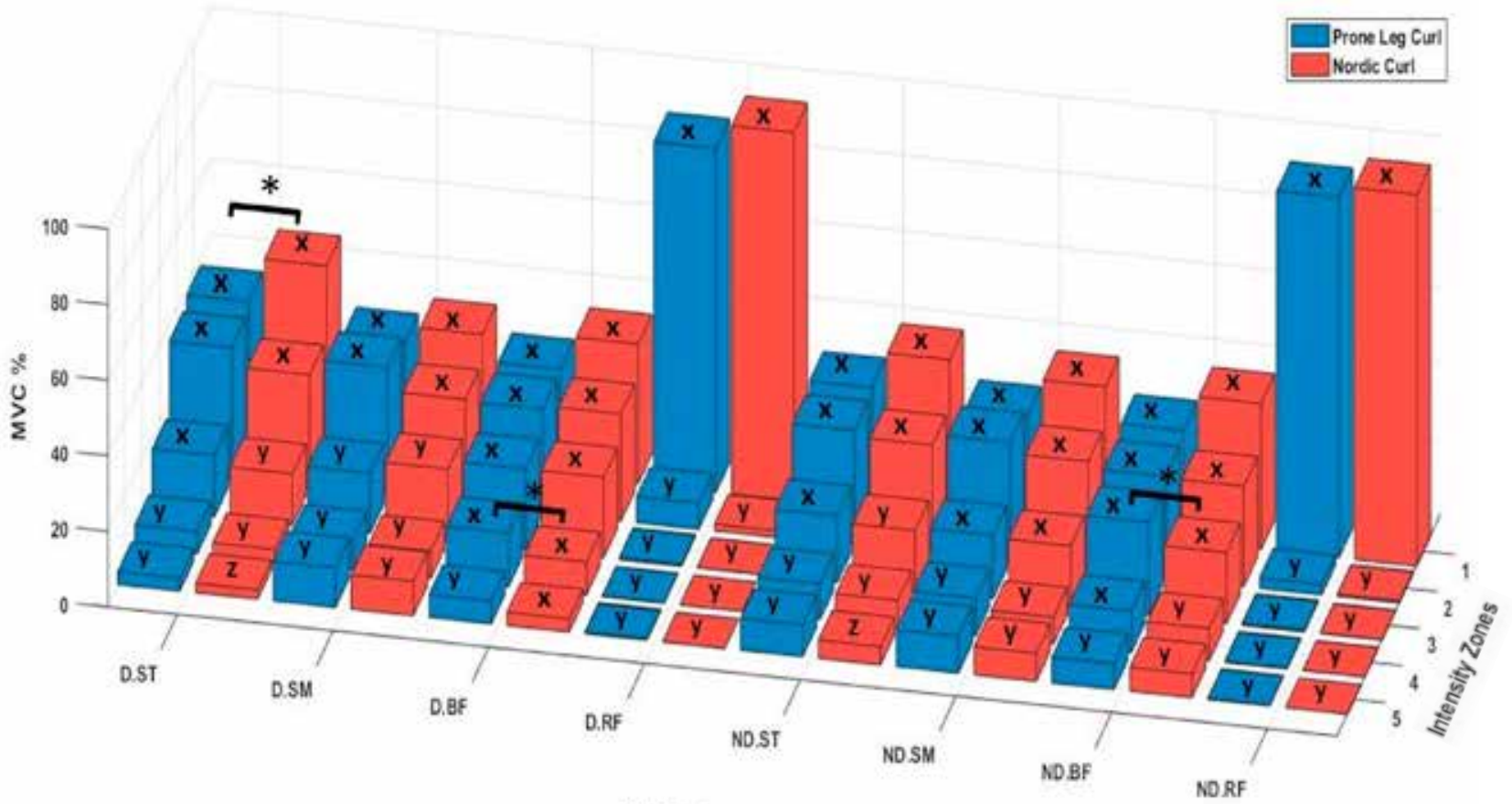

Muscles

Figure 7. Comparison of activity rates of the muscles in 5 intensity zones during the PLC and NC Exercises * Symbol refers to the significance of the difference between the PLC and NC $(p<0.05)$. The letters refer to the significance of the difference between activity rates in each intensity zone $(p<0.05)$. D.ST: Dominant semitendinosus, D.SM: Dominant semimembranosus, D.BF: Dominant Biceps femoris, D.RF: Dominant rectus femoris, ND.ST: Nondominant semitendinosus, ND.SM: Nondominant semimembranosus, ND.BF: Nondominant bicepsfemoris, ND.RF: Nondominant rectus femoris. 


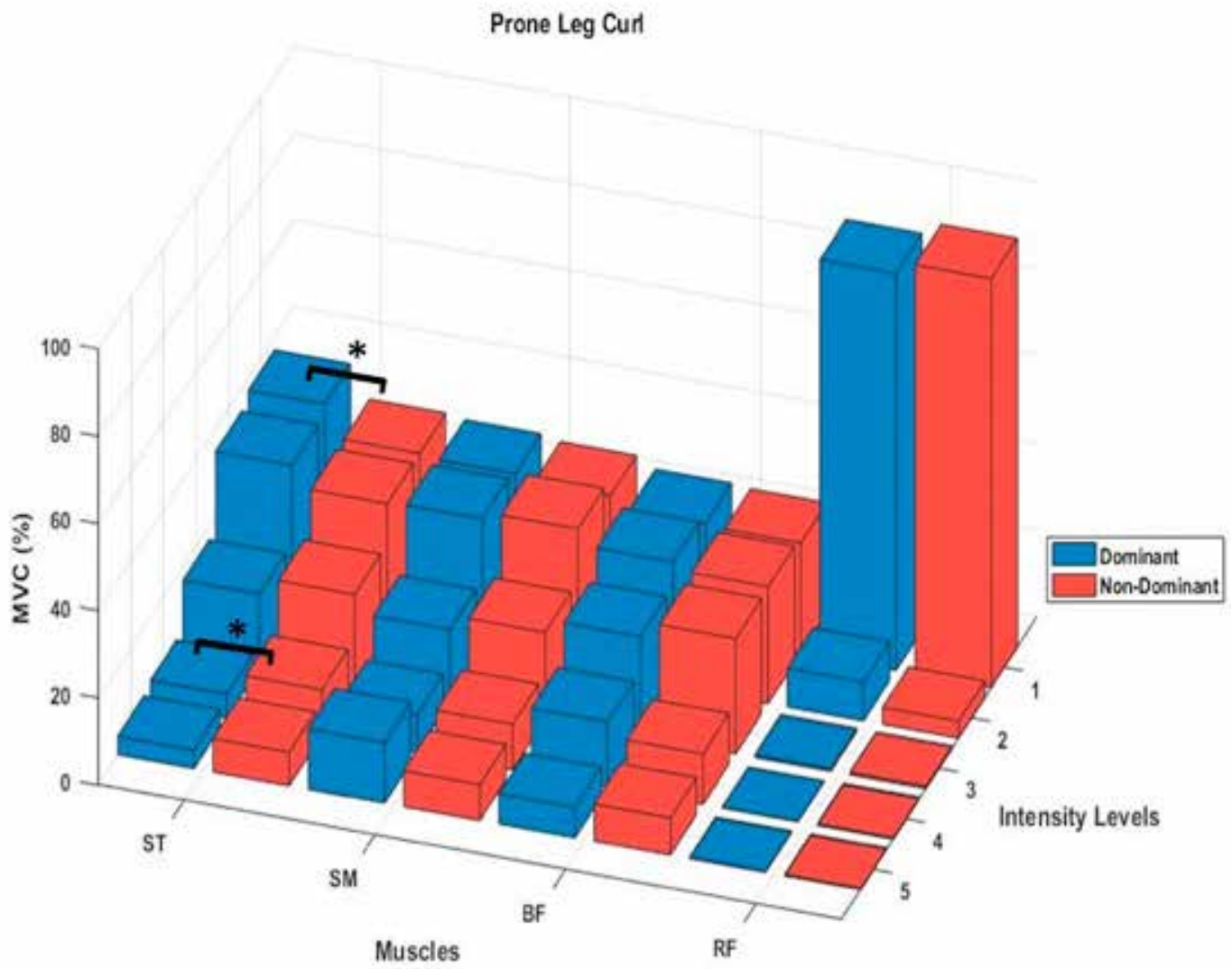

Figure 8. Comparison of activity rates of $D$ and ND legs in the five intensity zones for the PLC exercise * Symbol refers to the significance of the difference between the D leg and ND leg $(p<0.05)$. ST: Semitendinosus, SM: Semimembranosus, BF: Biceps femoris, RF: Rectus femoris

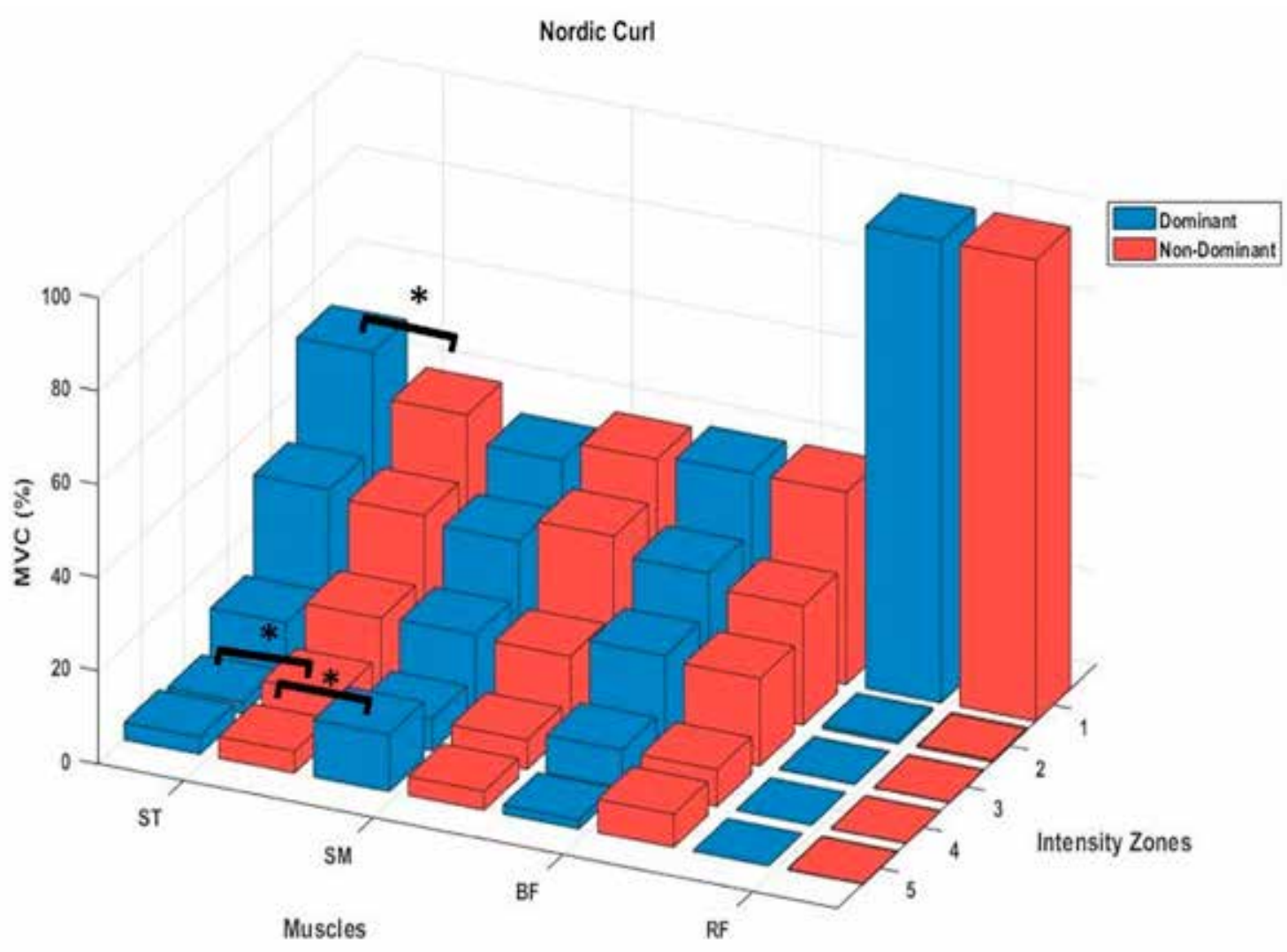

Figure 9. Comparison of activity rates of $D$ and ND legs in the five intensity zones for the NC exercise * There was a significant difference between the D leg and ND leg $(p<0.05)$. ST: Semitendinosus, SM: Semimembranosus, BF: Biceps femoris, RF: Rectus femoris. 
$(\mathrm{D}: 2 \%, \mathrm{ND}: 8 \%)(\mathrm{p}<0.05)$. The activity rate of the $\mathrm{D}$ leg was higher for the SM muscle in the fifth intensity zone $(\mathrm{D}: 12 \%, \mathrm{ND}: 4 \%)(\mathrm{p}<0.05)$.

\section{Discussion}

This study aims to examine the muscle responses of football players to the PLC and NLC exercises by electromyography. The PLC and $\mathrm{NC}$ exercises were performed 6 times and it was observed that the PLC exercise took place in a shorter time. Supporting this study, Jones et al. [36] observed higher peak velocity and average velocity values in the power clean exercise performed on the machine in their study, where they compared the kinetic responses to free weights and power cleans exercise on the machine.

Another study compared the kinematic, kinetic and muscle activity between pneumatic and free weight resistance. It has been found that the work in the pneumatic machine is performed with a larger average and maximum speed compared to free weights [37]. This situation stems from the fact that both exercises are mechanically different from each other. The PLC exercise occurs only in the knee joint while more joints participate in the NC exercise. The $\mathrm{NC}$ appears to be a more complex and advance exercise and it is slower than the PLC exercise in the application phase. Another factor is that the time between repetitions is longer in the $\mathrm{NC}$ exercise therefore it is thought that the total duration of the exercise is longer.

According to cumulative integrated EMG data in the PLC and NC exercises, it was observed that the activation of the muscles throughout the total exercise was similar. Pedersen et al. [38] their study comparing flywheel inertial leg curl and nordic hamstring exercises on football players, concluded that the muscle activity of both exercises in the concentric phase was similar. In their study, Schick et al. [39] found that the bench press exercise performed with free weight showed more muscle activation in the medial deltoid compared to the smith machine bench press exercise. This may be due to the same resistance during both exercises.

When the activity rates of the muscles in the intensity zones of the PLC and NC exercises were compared, a higher activation rate was observed only for the nondominant ST muscle in the first intensity zone in the $\mathrm{NC}$ exercise. In a study examining muscle activation during Nordic curl exercise, Monajati et al. [8] found that the activation of the hamstring muscles increased, the knee angle remained high between 60 and $40^{\circ}(>70 \%)$, and then dropped to $27 \%$ of the maximal isometric voluntary contraction at the end of the exercise. Hamstring muscle activation was examined during the Nordic hamstring exercise, which was performed as 6 sets and 5 repetitions in amateur football players, and the hamstring muscle activity in the descent phase gradually increased as the number of sets increased. These increases were seen in the first half of the range of motion [40]. The reason for this difference is thought to be due to the higher muscle activation in the NC movement between repetitions, especially in the low intensity zone. It was observed that the PLC exercise showed a higher activity rate in the third and fourth intensity zones. Supporting the findings of this study, Scmitt et al. [41] found that the biceps femoris muscle was most active during leg curl exercise compared to other hamstring exercises. Oliver and Dougherty [42] examining the activity of hamstring and gluteus maximus muscles during razor curl and traditional prone hamstring curl exercises with EMG, found that more muscle activation was seen during prone hamstring curl exercise. In another study, Pedersen et al. [38] found that the flywheel inertial leg curl exercise in the concentric phase showed higher muscle activation compared to the Nordic curl. Schoenfeld et al. [43] examined the muscle activation in the proximal and distal directions of the medial and lateral hamstrings on two separate hamstring exercises (stiff-legged deadlift, and the lying leg curl), and they found that the lower lateral and lower medial hamstring were activated during the Lying leg curl. Hegyi et al. [44] examined various hamstring exercises with high-intensity electromyography, and found that one of the exercises with the highest activation in both the eccentric phase and the concentric phase was the Prone Leg Curl. In this direction, the PLC exercise can be preferred to provide higher muscle activation. Again, the activation rate of each muscle in the 5 intensity zones during each exercise differed from each other. Activity rate tended to decrease from the low intensity zone to the high intensity zone. The reason for this is that during the six repetitions, we included not only the phases in which the muscle was active, but also the time between repetitions, so the muscles may have worked more at lower intensity. Comparing the activation rates between D and ND legs in each intensity zone during the PLC exercise, the activity rate of the D leg in the first zone and the ND leg in the fourth zone was found to be the highest. In their study in which they measured the strength and fatigue of hip abductors with EMG, Jacobs et al. [45] found that hip adduction peak torque was higher in the dominant leg compared to the nondominant leg. In the same vein, Mondal et al. [46] concluded that the dominant leg showed a higher level of EMG activity in their study in which they measured EMG activities in resting standing positions in D and ND legs on 30 football players. In a study examining the contralateral power imbalances in the $\mathrm{D}$ and ND lower extremities in soccer players, they found that the $\mathrm{D}$ leg produced a higher power output at $40 \%$ and $60 \%$ of the maximal force in the knee extensor and flexor muscles [47].

When the activity rates between D and ND legs during the NC exercise were compared in each intensity zone, the $\mathrm{D}$ activity rate was found to be higher in the first and fifth intensity zones, while the activity rate of the ND leg in the fourth intensity zone was found to be higher. Vaisman et al. [22] measured the muscle power of the dominant and non-dominant legs on two groups, non-athletes and single leg dominant professional soccer players. They could not find a significant difference between the powers of both the single leg dominant professional soccer players' $D$ and ND leg max powers. Lanshammar et al. [48] evaluated quadriceps and hamstring muscle strengths in the D and 
ND legs in women aged 20-39 with maximum isokinetic concentric contractions at an angular velocity of $90 \%$. They found that muscle strength in knee flexors was $86 \%$ weaker in the dominant leg, whereas it was 5.3\% stronger in knee extensors compared to the non-dominant leg. As a result, when we look at the PLC and NC exercises in general, we can say that the D and ND leg work at a similar rate.

\section{Conclusions}

The study revealed that the PLC exercise took shorter time than the NC exercise. According to the cumulative EMG data results, all muscles showed similar activity during both exercises. Upon comparing the activity rates of muscles in the PLC and NC exercises in the five intensity zones, the $\mathrm{NC}$ exercise showed more activity in the first intensity zone. However, the PLC showed more activity exercise in the third and fourth intensity zone. While the activation rate of the D leg was higher in the first intensity zones during the PLC exercise, the activity rate of the ND leg was observed to be higher in the fourth intensity zone. While the activity rate of the D leg was higher in the first intensity zones during the PLC exercise, the activity rate of the ND leg was observed to be higher in the fourth intensity zone. During the NC exercise, the activation rate of the $\mathrm{D}$ leg in the first and fifth intensity zone was higher, whereas the activation rate of the ND leg was observed to be higher in the fourth intensity zone. PLC exercises can be preferred to provide high muscle activity in a short time. The study showed that there were no big differences between the D and ND legs and the exercise provided a balanced muscle activity.

\section{Disclosure of interest}

The authors report no conflict of interest.

\section{Acknowledgements}

The authors thank to Cem YILDIRIM who check the English of the manuscript.

\section{Funding}

This study was supported by the TUBITAK 2209A 2019/2 University Students Research Projects Support Program.

\section{References}

1. Rouissi M, Chtara M, Owen A, Chaalali A, Chaouachi A, Gabbett $\mathrm{T}$, et al. Effect of leg dominance on change of direction ability amongst young elite soccer players. $J$ Sports Sci. 2016;34:6:542-8. https://doi.org/10.1080/02640414.2015.1129432

2. Little T, Williams AG. Specificity of acceleration, maximum speed, and agility in professional soccer players. J Strength Cond Res. 2005;19(1):76-78. https://doi.org/10.1519/00124278-200502000-00013

3. Özen G, Atar Özdermir, Yurdakul H, Pehlivan B, Koç H. The effect of pre-season football training on hematological parameters of well-trained young male football players. Pedagogy of Physical Culture and Sports. 2020;24(6):303-9. https://doi.org/10.15561/26649837.2020.0605

4. Carling C, Gall FL, Reilly TP. Effects of Physical Efforts on Injury in Elite Soccer. Int J Sports Med, 2010;31:180-5. https://doi.org/10.1055/s-0029-1241212

5. Van Der Horst N, Smits DW, Petersen J, Goedhart EA, Backx FJG.The PreventiveEffect of the Nordic Hamstring Exercise on Hamstring Injuries in Amateur Soccer Players: A Randomized Controlled Trial. Am J Sports Med. 2015;43(6):1316-23. https://doi.org/10.1177/0363546515574057

6. Brughelli M, Nosaka K, Cronin J. Application of eccentric exercise on an Australian rules football player with recurrent hamstring injuries. Phys Ther Sport. 2009;10(2):75-80. https://doi.org/10.1016/j.ptsp.2008.12.001

7. Marušič J, Šarabon N. Comparison of electromyographic activity during nordic hamstring exercise and exercise in lengthened position. Eur J Transl Myol. 2020;30(2):234-9. https://doi.org/10.4081/ejtm.2020.8957

8. Monajati A, Larumbe-Zabala E, Goss-Sampson M, Naclerio Naclerio F. The effectiveness of injury prevention programs to modify risk factors for non-contact anterior cruciate ligament and hamstring injuries in uninjured team sports athletes: A systematic review. PLoS One. 2016;11(5):1-15. https://doi.org/10.1371/journal.pone.0155272

9. Woods C,Hawkins RD, Maltby S, Hulse M, Thomas A, Hodson
A. The football association medical research programme: An audit of injuries in professional football - analysis of hamstring injuries. Br J Sports Med. 2004;38(1):36-41. https://doi.org/10.1136/bjsm.2002.002352

10.Arnason A, Andersen TE, Holme I, Engebretsen L, Bahr R. Prevention of hamstring strains in elite soccer: An intervention study. Scand J Med Sci Sport. 2008;18(1):40-8. https://doi.org/10.1111/j.1600-0838.2006.00634.x

11. Hallén A, Ekstrand J. Return to play following muscle injuries in professional footballers. JSports Sci. 2014;32(13):1229-36. https://doi.org/10.1080/02640414.2014.905695

12.Van Doormaal MCM, Van Der Horst N, Backx FJG, Smits DW, Huisstede BMA. No relationship between hamstring flexibility and hamstring injuries in male amateur soccer players. Am J Sports Med. 2017;45(1):121-6. https://doi.org/10.1177/0363546516664162

13.Orchard J, Seward H. Epidemiology of injuries in the Australian football league, seasons 1997-2000. Br J Sports Med. 2002;36:39-45. https://doi.org/10.1136/bjsm.36.1.39

14.Ditroilo M, De Vito G, Delahunt E. Kinematic and electromyographic analysis of the Nordic Hamstring Exercise. J Electromyogr Kinesiol. 2013;23(5):1111-8. https://doi.org/10.1016/j.jelekin.2013.05.008

15.Freckleton G, Cook J, Pizzari T. The predictive validity of a single leg bridge test for hamstring injuries in Australian rules football players. Br J Sports Med. 2014;48(8):713-7. https://doi.org/10.1136/bjsports-2013-092356

16.Dadebo B, White J, George KP. A survey of flexibility training and hamstring strains in professional football clubs in England. Br J Sports Med. 2004;38(4):388-94. https://doi.org/10.1136/bjsm.2002.000044

17.Opar DA, Williams MD, Shield AJ. Hamstring strain injuries: factors that lead to injury and re-Injury. Sport Med. 2012;42(3):209-26. https://doi.org/10.2165/11594800-000000000-00000

18.Malliaropoulos N, Panagiotis T, Jurdan M, Vasilis K, Debasish $\mathrm{P}$, Peter $\mathrm{M}$, et al. Muscle and intensity based hamstring 
exercise classification in elite female track and field athletes: implications for exercise selection during rehabilitation. Open Access J Sport Med. 2015;6 209-217:209-217. https://doi.org/10.2147/OAJSM.S79189

19.Ernlund L, Vieira L de A. Hamstring injuries: update article. Rev Bras Ortop (English Ed), 2017;52(4):373-82. https://doi.org/10.1016/j.rbo.2017.05.001

20.Ekstrand J, Healy JC, Waldén M, Lee JC, English B, Hägglund M. Hamstring muscle injuries in professional football: The correlation of MRI findings with return to play. $B r \quad J$ Sports Med. 2012;46(2):112-7. https://doi.org/10.1136/bjsports-2011-090155

21.Croisier JL, Ganteaume S, Binet J, Genty M, Ferret JM. Strength imbalances and prevention of hamstring injury in professional soccer players: A prospective study. Am J Sports Med. 2008;36(8):1469-75. https://doi.org/10.1177/0363546508316764

22.Vaisman A, Guiloff R, Rojas J, Delgado I, Figueroa D, Calvo R. Lower limb symmetry: comparison of muscular power between dominant and nondominant legs in healthy young adults associated with single-legdominant sports. Orthop J Sport Med. 2017;5(12):1-6. https://doi.org/10.1177/2325967117744240

23.Kannus P, Alosa D, Cook L, Johnson RJ, Renström P, Pope M, et al. Effect of one-legged exercise on the strength, power and endurance of the contralateral leg - A randomized, controlled study using isometric and concentric isokinetic training. Eur J Appl Physiol Occup Physiol. 1992;64(2):117-26. https://doi.org/10.1007/BF00717948

24.López-Calbet J, Dorado C, Díaz-Herrera P, RodríguezRodríguez P. High femoral bone mineral content and density in male football (soccer) players. Med Sci Sport Exerc. 2001;33(10):1682-1687. https://doi.org/10.1097/00005768-200110000-00011

25.Zakas A. Bilateral isokinetic peak torque of quadriceps and hamstring muscles in professional soccer players with dominance on one or both two sides. J Sports Med Phys Fitness. 2006;46:28-35.

26.Ayala F, López-Valenciano A, Gámez Martín JA, De Ste Croix M, Vera-Garcia FJ, García-Vaquero MDP, et al. Preventive model for hamstring injuries in professional soccer: Learning algorithms. Int J Sports Med. 2019;40(5):344-53. https://doi.org/10.1055/a-0826-1955

27.Askling C, Karlsson J, Thorstensson A. Hamstring injury occurrence in elite soccer players after preseason strength training with eccentric overload. Scand J Med Sci Sport. 2003;13(4):244-50. https://doi.org/10.1034/j.1600-0838.2003.00312.x

28.Brooks JHM, Fuller CW, Kemp SPT, Reddin DB. Incidence, risk, and prevention of hamstringmuscleinjuriesinprofessional rugby union. Am J Sports Med. 2006;34(8):1297-306. https://doi.org/10.1177/0363546505286022

29.Petersen J, Thorborg K, Nielsen MB, Budtz-Jørgensen E, Hölmich P. Preventive effect of eccentric training on acute hamstring injuries in men's soccer: A cluster-randomized controlled trial. Am J Sports Med. 2011;39(11):2296-303. https://doi.org/10.1177/0363546511419277

30.Gabbe BJ, Branson R, Bennell KL. A pilot randomised controlled trial of eccentric exercise to prevent hamstring injuries in community-level Australian Football. J Sci Med Sport. 2006;9(1-2):103-9. https://doi.org/10.1016/j.jsams.2006.02.001

31.Mjølsnes R, Arnason A, Østhagen T, Raastad T, Bahr R. A 10-week randomized trial comparing eccentric vs. concentric hamstring strength training in well-trained soccer players. Scand J Med Sci Sport. 2004;14(5):311-7. https://doi.org/10.1046/j.1600-0838.2003.367.x

32.Iga J, Fruer CS, Deighan M, Croix MDS, James DVB. Nordic hamstrings exercise - Engagement characteristics and training responses. Int J Sports Med. 2012;33(12):1000-4. https://doi.org/10.1055/s-0032-1304591

33.Messer DJ, Bourne MN, Williams MD, Najjar AAL, ShieldAJ. Hamstring muscle use in women during hip extension and the nordic hamstring exercise: A functional magnetic resonance imaging study.JOrthop Sports Phys Ther. 2018;48(8):607-12. https://doi.org/10.2519/jospt.2018.7748

34.Hermens, H. J., Freriks, B., Disselhorst-Klug, C., \& Rau G (2000). Development of recommendations for SEMG sensors and sensor placement procedures. $J$ Electromyogr Kinesiol. 2000;10(5):361-74. https://doi.org/10.1016/S1050-6411(00)00027-4

35.Konrad P. The ABC of EMG. A practical introduction to kinesiological electromyography. 2005.

36.Jones RM, Fry AC, Weiss LW, Kinzey SJ, Moore CA. Kinetic ComparisonofFreeWeightandMachinePowerCleans.Journal of Strength and Conditioning Research, 2008;22:1785-9. https://doi.org/10.1519/JSC.0b013e318185f068

37.Frost DM, Cronin JB, Newton RU. A comparison of the kinematics, kineticsandmuscleactivitybetweenpneumaticand freeweightresistance.EurJApplPhysiol.2008;104(6):937-56. https://doi.org/10.1007/s00421-008-0821-8

38.Pedersen H, Saeterbakken AH, Vagle M, Fimland MS, Andersen V. Electromyographic comparison of flywheel inertial leg curl and nordic hamstring exercise among soccer players. Int J Sports Physiol Perform. 2021;16(1):97-102. https://doi.org/10.1123/ijspp.2019-0921

39.Schick EE, Coburn JW, Brown LE, Judelson DA, Khamoui $\mathrm{AV}$, Tran $\mathrm{T}$, et al. A Comparison Of Muscle Activation Between A Smith Machine And Free Weight Bench Press: Journal of Strength and Conditioning Research, 2010;24:1. https://doi.org/10.1097/01.JSC.0000367207.18161.d7

40.Marshall, P. W., Lovell, R., Knox, M. F., Brennan, S. L., \& Siegler JC. Hamstring fatigue and muscle activation changes during six sets of nordic hamstring exercise in amateur soccer players. 2015;3124-33. https://doi.org/10.1519/JSC.0000000000000966

41.Schmitt KM. Electromyographic comparison of the hamstring muscles during various exercises [dissertation on the internet]. December, 2017 [cited 2020 Dec 7]. Available from: https://minds.wisconsin.edu/bitstream/handle/1793/76904/ Schmitt_Kayla_Thesis.pdf? sequence $=1 \&$ isAllowed $=y$

42. Oliver GD, Dougherty CP. Comparison of Hamstring and Gluteus Muscles Electromyographic Activity while Performing the Razor Curl vs. the Traditional Prone Hamstring Curl. Journal of Strength and Conditioning Research, 2009;23:2250-5. https://doi.org/10.1519/JSC.0b013e3181b8d34b

43.Schoenfeld BJ, Contreras B, Tiryaki-Sonmez G, Wilson JM, Kolber MJ, Peterson MD. Regional differences in muscle activation during hamstrings exercise. J Strength Cond Res. 2015;29(1):159-64. https://doi.org/10.1519/JSC.0000000000000598

44.Hegyi A, Csala D, Péter A, Finni T, Cronin NJ. Highdensity electromyography activity in various hamstring exercises. Scand J Med Sci Sport. 2019;29(1):34-43. https://doi.org/10.1111/sms.13303

45.Jacobs C, Uhl TL, Seeley M, Sterling W, Goodrich L. Strength and fatigability of the dominant and nondominant hip abductors. $J$ Athl Train. 2005;40(3):203-6.

46.Mondal S, Chhangte Z, Gayen A, Chatterjee S. Dominant 
and Non-Dominant Leg Muscle Electrical Activity of Soccer Players: A Preliminary Study. Int Ref J Eng Sci. 2014;3(4):65-9.

47.Blache Y, Monteil K. Contralateral strength imbalance between dominant and non-dominant lower limb in soccer players. Sci Sport. 2012;27(3):1-8. https://doi.org/10.1016/j.scispo.2011.08.002

48.Lanshammar K, Ribom EL. Differences in muscle strength in dominant and non-dominant leg in females aged 20-39 years -A population-based study. Physical Therapy in Sport, 2011;12:76-9. https://doi.org/10.1016/j.ptsp.2010.10.004

\section{Information about the authors:}

Murat Çilli; (Corresponding author); https://orcid.org/0000-0002-9027-363X; mcilli@subu.edu.tr; Faculty of Sport Sciences, Sakarya University of Applied Sciences; Sakarya, Turkey.

Merve N. Yaşar; http://orcid.org/0000-0003-1334-4630; merveyasar@subu.edu.tr; Faculty of Sport Sciences, Sakarya University of Applied Sciences; Sakarya, Turkey.

Onur Çakir; https://orcid.org/0000-0001-7625-5067; cakirron@gmail.com; Faculty of Sport Sciences, Sakarya University of Applied Sciences; Sakarya, Turkey.

\section{Cite this article as:}

Çilli M, Yaşar NM, Çakir O. Electromyographic responses to Nordic curl and prone leg curl exercises in football players. Physical Education of Students, 2021;25(5):288-298.

https://doi.org/10.15561/20755279.2021.0505

This is an Open Access article distributed under the terms of the Creative Commons Attribution License, which permits unrestricted use, distribution, and reproduction in any medium, provided the original work is properly cited http://creativecommons.org/licenses/by/4.0/deed.en

Received: 30.08.2021

Accepted: 05.10.2021; Published: 30.10.2021 